\title{
AGRESTE SOLIDÁRIO
}

Thiago José de Azevêdo Loureiro ${ }^{1}$

Anna Karina Vasconcelos Nascimento ${ }^{2}$

Leandro da Cruz Martins ${ }^{3}$

\section{RESUMO}

O Projeto Agreste Solidário tem como principal objetivo promover ações junto às comunidades carentes da Região Agreste do RN para contribuir com a melhoria da qualidade de vida dos cidadãos. A cada quatro meses são arrecadados alimentos, roupas, brinquedos para doação às comunidades carentes de cada município contemplado no projeto. Os participantes são responsáveis pela divulgação do projeto, coleta, armazenamento e distribuição das doações. Cada município terá um grupo de voluntários e no mínimo um posto de coleta.

Palavras-chave: região agreste. responsabilidade social. voluntariado

\section{INTRODUÇÃO}

A pobreza é um fator visível numa sociedade onde temos ciência de que várias pessoas vivem de forma inadequada, ou seja, não possuem sequer boas condições de alimentação e moradia. Assim, percebe-se que nessas condições de vida, é difícil aos cidadãos conquistarem seus objetivos pessoais e profissionais, tendo em vista que as dificuldades são muito maiores se compararmos com aquelas que já possuem as condições básicas para viver.

No Rio Grande do Norte, a realidade é bastante semelhante. Com isso, surgiu a ideia da criação do Projeto de Extensão denominado Agreste Solidário, com a perspectiva de promover benefícios aos cidadãos das comunidades carentes da Região Agreste do Rio Grande Norte, porém até o momento as ações realizadas aconteceram no município de Nova Cruz, cidade esta onde se encontra o nosso Campus. A partir de então, através da Prefeitura Municipal da cidade de Nova Cruz, buscou-se coletar dados que mostrassem a realidade desse município e assim pôde-se compreender a realidade das famílias que foram e serão beneficiadas futuramente.

Segundo registros do Ministério do Desenvolvimento Social e Combate à Fome, o Município de Nova Cruz possui um quantitativo de 5.778 famílias beneficiárias do Programa Bolsa Família, isso representa $57,96 \%$ da população do Município. Através desses dados percebe-se como esse Município encontra-se. A partir daí começaram a surgir as ideias para colocar em prática o Projeto.

O Projeto encaminha-se da seguinte maneira: primeiramente foram indicados os meses nos quais as ações iriam ser realizadas, a escolha se deu de acordo com os eventos tradicionais do nosso País. Assim, foi escolhido o mês de abril no

1 Professor do campus Nova Cruz, graduado em administração e emestre em Engenharia da produção.

2 Assistente em administração do Campus Nova Cruz.

3 Aluno do curso técnico integrado em informática e bolsista do projeto. 
qual acontece a Semana Santa, onde são arrecadados e distribuídos alimentos; o mês de outubro, no qual temos o dia das crianças, em que são arrecadados e distribuídos alimentos e brinquedos e, por último, o mês de dezembro, devido às festividade natalinas, em que são arrecadados e distribuídos alimentos. Essas distribuições acontecem nas semanas referentes a essas festividades, proporcionando assim, que as famílias beneficiadas possam passar esses momentos especiais de uma forma melhor.

As arrecadações acontecem durante uma semana, a distribuição dependerá da quantidade arrecadada. As comunidades contempladas serão escolhidas pela equipe do projeto e obedecerão a rodízios. Serão realizadas reuniões para planejamento e socialização das atividades do projeto. Os postos de arrecadação ficarão abertos o dia todo, cada município terá sua equipe de voluntários, mas se necessário equipes de outros municípios poderão ajudar.

\section{DESENVOLVIMENTO DO PROJETO}

A primeira ação do Projeto aconteceu no mês de outubro de 2013, nesse momento foram beneficiadas aproximadamente 60 crianças e 9 cestas destinadas as famílias dessas crianças. Isso aconteceu em duas creches do Município e na Pastoral do Menor. Podemos observar, nas das imagens, algumas crianças que receberam as doações.

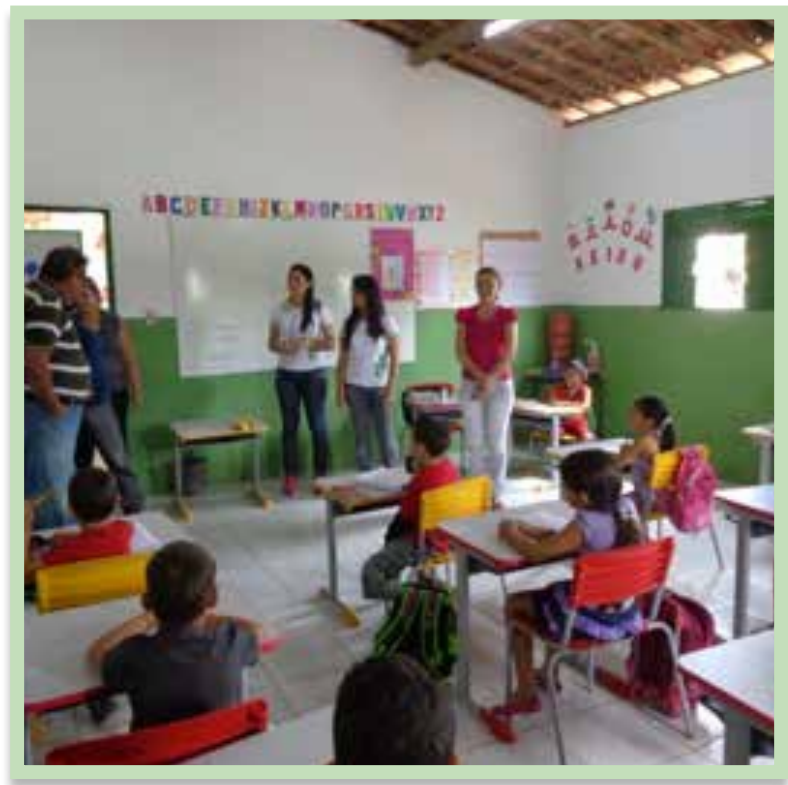

Figura 1: creche Serrote dos Bezerras

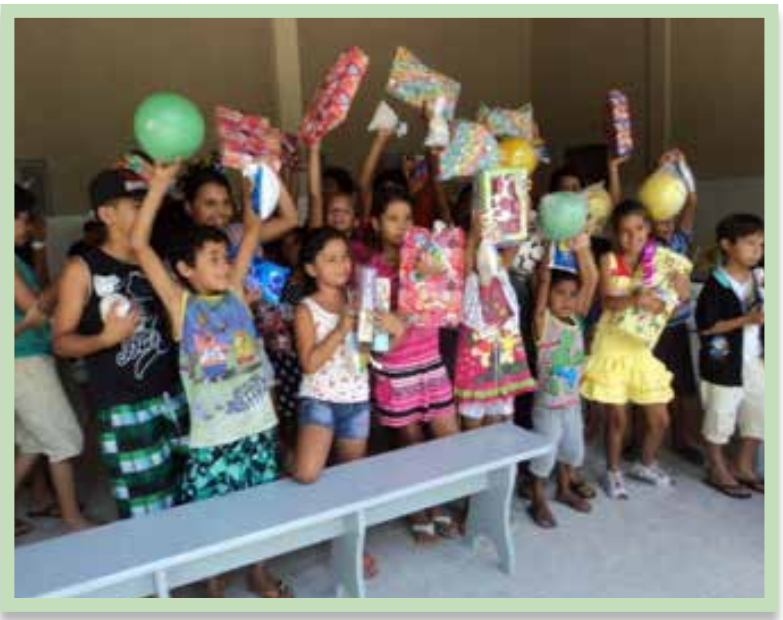

Figura 2: Pastoral do Menor

A segunda ação ocorreu no mês de dezembro de 2013, beneficiando a creche Maria Tavares, com aproximadamente 35 cestas. Nessa ação, houve doação de cestas básicas para as famílias das crianças que estudam nessa creche. Adiante podemos visualizar momentos da segunda ação do Projeto Agreste Solidário.

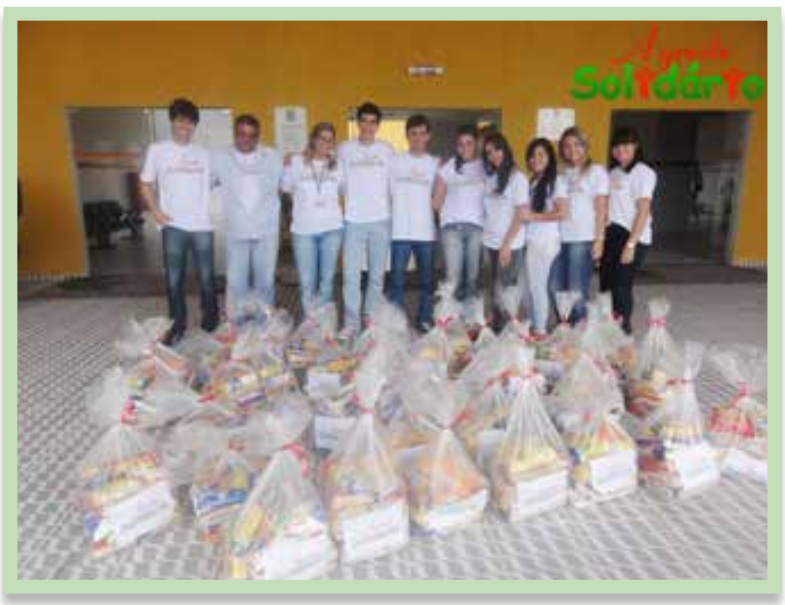

Figura 3: ação de componentes do Projeto

A cada ação que vem acontecendo a quantidade de doações aumenta, com isso, na terceira ação do Agreste Solidário, que aconteceu no mês de março de 2014, foi doado cerca de 60 cestas básicas. Dessa vez, foram beneficiadas as famílias dos alunos da creche Ednólia Câmara de Melo, como podemos observar nas Figuras 5 e 6. 


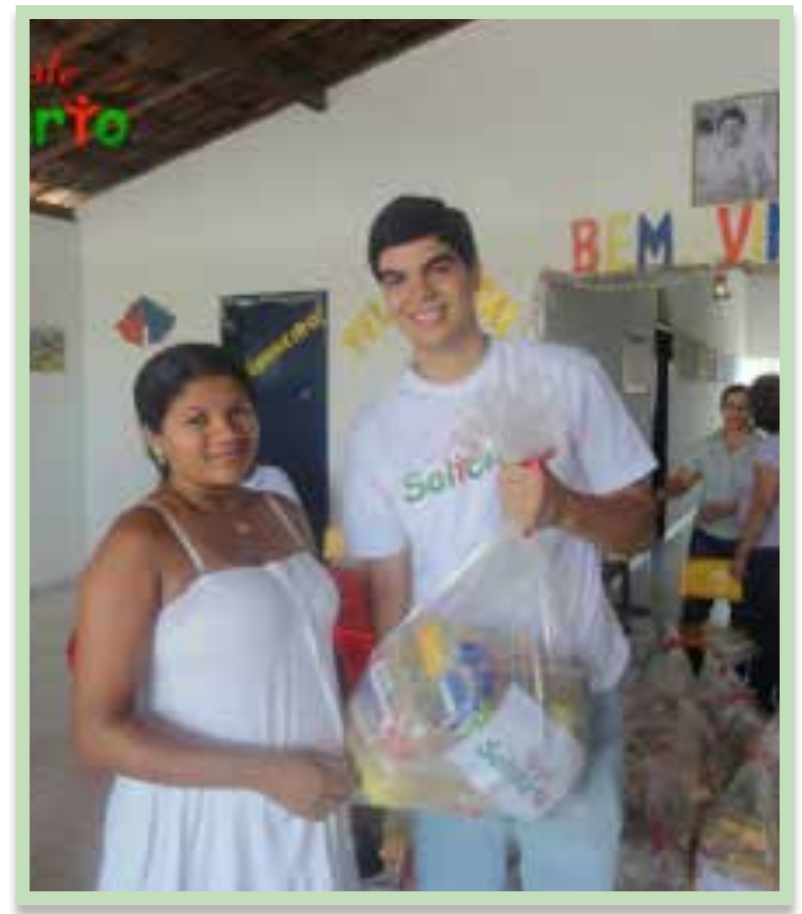

Figura 4: entrega das doações

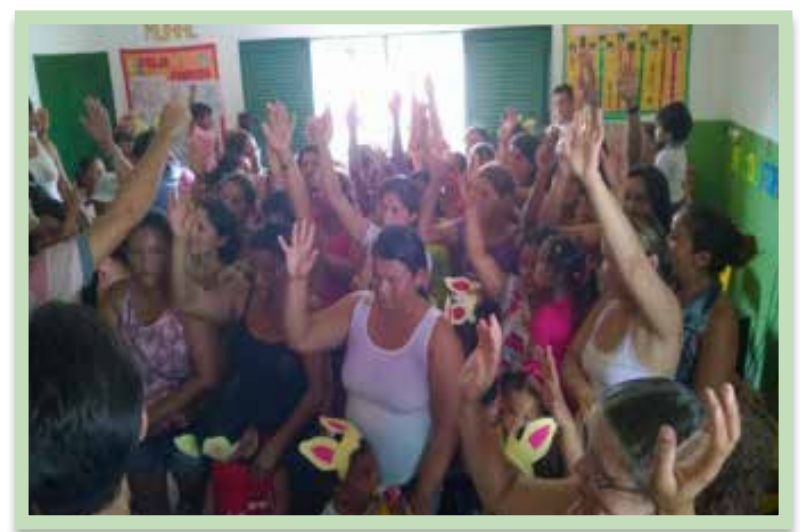

Figura 5: famílias beneficiadas

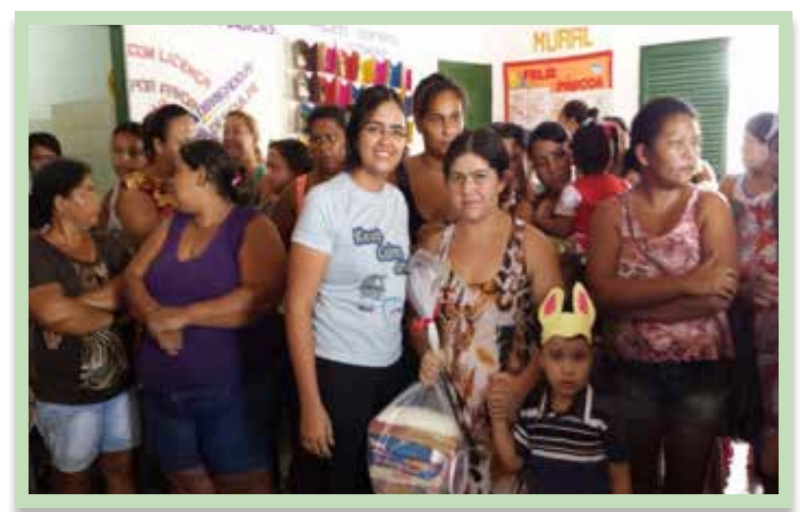

Figura 6: entrega das doações

\section{CONCLUSÃO}

Esse projeto tem demonstrado aumento na partipação de alunos e servidores do Campus em ações de solidariedade e por isso pretende-se dar continuidade, tendo em vista que o mesmo tem como eixo central fazer com que essas pessoas, que possuem baixas condições financeiras, possam passar essas festividades, nas quais as doações acontecem, de forma melhor e ver que, apesar de tudo, existem pessoas que acreditam nelas e veem que ajudar é um ato de humanidade.

A partir da próxima ação do Projeto Agreste Solidário, pretende-se expandi-lo, ou seja, beneficiar outro Município, pois como foi citado anteriormente, esse é o objetivo. Assim, percebese que além do que já foi feito, existem muitas coisas a serem feitas ainda; dessa forma, na proporção que o Projeto vem crescendo, esperase aumentar a cada ação o número de crianças e consequentemente o de famílias beneficiadas.

\section{REFERENCIAS}

Disponível em: <http://mds.gov.br/>. Acesso em: 16 jul. 2014. 